\title{
OS ESFORÇOS DE INOVAÇÃO E SUA RELAÇÃO COM ALGUNS INDICADORES DE DESEMPENHO DO NEGÓCIO
}

\section{THE INNOVATION EFFORTS AND ITS RELATIONSHIP WITH SOME BUSINESS PERFORMANCE INDICATORS}

\author{
Fernanda Lazzari* E-mail: fernandalazzari@hotmail.com \\ Rodrigo Eduardo Bampi* E-mail: rodrigoebampi@yahoo.com.br \\ Gabriel Sperandio Milan* E-mail: gsmilan@ucs.br \\ *Universidade de Caxias do Sul (UCS), Caxias do Sul, RS
}

Resumo: Os recursos disponíveis nas empresas, uma vez que sejam capazes de gerar valor, poderão promover uma vantagem comparativa da mesma em relação aos concorrentes, as quais se desenvolverão, em nível macro, por meio da qualidade superior, eficiência e eficácia e de inovações; e, em nível micro, com base em um desempenho financeiro superior. O estudo, a partir da adoção de técnicas de análises quantitativas (estatística descritiva e análise de regressão linear múltipla), observou, sob a perspectiva da Teoria da Vantagem Comparativa, que os esforços de inovação realizados pelas empresas brasileiras de capital aberto estão alinhados com uma performance superior das mesmas. Os resultados mostram que os indicadores de desempenho financeiro ROE e ROA apresentaram diferença significativa entre os grupos de empresas "Inovadoras" e "Sem Inovação.

Palavras-chave: Inovação. Teoria da Vantagem Comparativa. Indicadores de Desempenho. Desempenho Financeiro. Competitividade.

\begin{abstract}
Available resources, which are able to generate value, may promote a comparative advantage to the company in relation to its competitors. They might develop, at the macro level, by means of superior quality, efficiency and effectiveness and innovations; and, at micro level, based on superior financial performance. This study employing quantitative analyzes techniques (descriptive statistics and multiple linear regression analysis), identified that from a Theory of Comparative Advantage perspective, innovation efforts of Brazilian traded companies are aligned with its superior performance. The results show that the financial performance indicators ROE and ROA have a significant difference between "Innovative" and "No innovative" companies groups.
\end{abstract}

Keywords: Innovation. Comparative Advantage Theory. Performance Indicators. Financial Performance. Competitiveness.

\section{INTRODUÇÃO}

Os fundamentos da Teoria da Vantagem Comparativa são capazes de melhor explicar o micro e o macro fenômeno que ocorrem nas empresas (firmas) em comparação à Teoria Neoclássica da competição perfeita. Enquanto a Teoria Neoclássica prevê uma demanda de mercado homogênea, um acesso à informação 
de forma fácil e sem custo, por parte dos agentes (ou atores) econômicos, além de uma perfeita mobilidade e homogeneidade dos recursos das empresas, a Teoria da Vantagem Comparativa pressupõe que a demanda entre os setores da economia é heterogênea, as informações necessárias aos agentes econômicos é assimétrica e possui um custo de aquisição e que os recursos também são heterogêneos e não totalmente passíveis de mobilidade (HUNT; MORGAN, 1995).

Entendendo que os recursos são os elementos tangíveis e intangíveis que fazem com que as empresas possam oferecer ao mercado algo de valor (BARNEY, 1991), um produto e/ou em serviço, a Visão Baseada em Recursos (VBR) passa a fornecer elementos para uma melhor compreensão da vantagem comparativa entre as empresas (WERNERFELT, 1984; 1995). Segundo a VBR, os recursos consistem em ativos, capacidades, processos organizacionais, atributos, informações e conhecimento, sendo que a sustentabilidade da vantagem competitiva presume quatro características destes recursos: devem ser raros, valiosos, difíceis de serem imitados e entendidos (vistos) pela concorrência e, além disso, não devem existir recursos substitutos estratégicos equivalentes para tais recursos (BARNEY, 1991).

Consoante isso, a Teoria da Vantagem Comparativa, proposta por Hunt e Morgan (1995), prevê que as empresas possuem recursos distintos entre si, os quais são geradores de uma posição de mercado diferenciada. Além disso, postula que esta posição diferenciada, que pode vir a se configurar em uma vantagem competitiva frente aos concorrentes, incide sobre diferentes resultados em termos de eficiência, qualidade superior e capacidade de gerar e de implementar inovações, além de resultar em uma performance financeira mais elevada.

Diante do exposto, o presente artigo visa analisar, sob a perspectiva da Teoria da Vantagem Comparativa, se os esforços de inovação realizados pelas empresas brasileiras de capital aberto e com ações negociadas na BOVESPA estão alinhados com um desempenho financeiro superior das mesmas. Para tanto, este estudo avaliou alguns indicadores financeiros (ROE, ROA e ROS) de um conjunto de empresas, verificando se as que são consideradas inovadoras (em função do número de patentes depositadas no INPI - Instituto Nacional de Propriedade Intelectual) possuem rentabilidade superior às demais. 
A fim de ilustrar os achados do estudo, este artigo apresenta, primeiramente, uma revisão teórica sobre o tema em questão, evidenciando, especialmente, os aspectos relativos à Teoria da Vantagem Comparativa, à VBR, aos conceitos relacionados à inovação e aos indicadores utilizados para avaliar o desempenho financeiro das empresas. Na sequência, é apresentado o método utilizado no estudo e, em seguida, os resultados observados. Por fim, é feita a discussão dos resultados e as considerações finais, limitações da pesquisa e sugestões de estudos futuros.

\section{REFERENCIAL TEÓRICO}

\subsection{Da Teoria Neoclássica à Teoria da Vantagem Comparativa}

Segundo a Teoria Neoclássica, o objetivo básico das empresas é maximizar o lucro. Para tanto, buscam a combinação dos fatores de produção disponíveis no mercado para produzir produtos comercializáveis. Considerando que as empresas sejam perfeitamente racionais e busquem a combinação ótima entre os fatores de produção, todas elas realizam suas atividades segundo a mesma combinação dos fatores, levando o sistema a uma situação de equilíbrio. Cabe salientar, porém, que em tais condições não se verificaria o lucro. Isto por que se qualquer agente tivesse acesso às condições ótimas de produção, o mercado teria novos empresários atraídos pelo lucro da produção de determinada oferta. Com uma maior concorrência, ocorreria uma redução nos preços do produto e, por consequência, uma redução do lucro do setor, até que este deixasse de existir. Além disso, na competição perfeita, a introdução de uma inovação em um produto de uma indústria tira o sistema do equilíbrio e o move para além de seu estado ideal.

Conforme Knight (1972), se todas as modificações ocorressem de acordo com as leis invariáveis e universalmente conhecidas, estas poderiam ser previstas por um período indefinido anteriormente à sua ocorrência. Com isso, as mesmas não transformariam a distribuição perfeita dos valores do produto entre os fatores contributivos e, por conseguinte, não se verificaria lucro (ou perda). É essa verdadeira incerteza que, impedindo o trabalho teoricamente perfeito das tendências 
da concorrência dá a forma característica de "empresa" à organização e proporciona retorno ao empresário (KNIGHT, 1972).

No entanto, uma vez que o lucro é evidenciado como uma rotina na economia, refuta-se a visão constante do equilíbrio do sistema. Como explicação de tal questão, inicialmente, é necessário considerar que a racionalidade dos indivíduos é limitada. Aliada a esta questão, também é fundamental salientar que as hipóteses de pleno conhecimento e informação perfeita não são confirmadas na prática, já que a obtenção de informação requer investimentos de recursos e, frente a isso, existem limites até onde uma empresa pode estar informada sobre o seu ambiente atual e suas perspectivas futuras (KNIGHT, 1972; HOSKISSON et al., 2009).

Dessa forma, os principais pressupostos da visão neoclássica passam a ser modificados, procurando tornar os modelos econômicos mais realistas. Como a realidade demonstra que os agentes econômicos são diferentes uns dos outros e não chegam a utilizar as condições ótimas de produção, dado que a racionalidade é limitada. Isto ocorre à medida que os agentes, por seu comportamento oportunista, buscam constantemente novas combinações produtivas, ou seja, novos produtos, novos métodos produtivos, novos mercados, novas fontes de matéria-prima ou nova forma de organização (WILLIAMSON, 1985; 1996).

No entendimento de Ricardo (1996), para valer a pena entrar em um mercado, é preciso "fazer diferente", caso contrário se estará sujeito às mesmas limitações das empresas que já estão competindo entre si. É este "fazer diferente" que irá gerar uma "curva" de produção diferente, o que permite, por exemplo, redução de custos ou vendas com maiores margens de lucro, em função de apresentar um produto diferenciado no mercado. Em acréscimo, Schumpeter (1912; 1942), ressalta que o empresário empreenderá em algo que está fora da fronteira da rotina, ou seja, um padrão diferente de ideia ou de atuação no mercado.

Seguindo essa linha de raciocínio, Hunt e Morgan (1995) apresentam os fundamentos da Teoria da Vantagem Comparativa. Segundo os autores, tal teoria é capaz de explicar melhor os elementos micro e macro do fenômeno da competição entre as empresas no mercado do que a Teoria Neoclássica da competição perfeita.

O fenômeno micro da heterogeneidade das empresas é evidente em uma economia baseada no mercado. Entre as indústrias e até mesmo entre países, é 
possível observar que as empresas diferem radicalmente no que diz respeito ao seu tamanho (porte), escopo, métodos de operação e desempenho financeiro (HUNT; MORGAN, 1995; BESANKO et al., 2012; BARNEY; HESTERLY, 2011).

Em função disso, os recursos das empresas, uma vez que sejam capazes de gerar valor, promovem uma vantagem comparativa da mesma em relação aos concorrentes, Ihes propiciando criar e manter uma possível vantagem competitiva sustentável e um posicionamento mercadológico diferenciado (PORTER, 1985; ROWE; BARNES, 1998; BESANKO et al., 2012; HOOLEY; PIERCY; NICOLAUD, 2011). Esta vantagem competitiva irá se desenvolver em nível macro, por meio de uma qualidade superior nos produtos e serviços, na eficiência dos processos e nas inovações; e, em nível micro, por meio de um desempenho financeiro mais elevado (HUNT; MORGAN, 1995), conforme representado na Figura 1.

Figura 1 - Modelo que representa a Teoria da Vantagem Comparativa

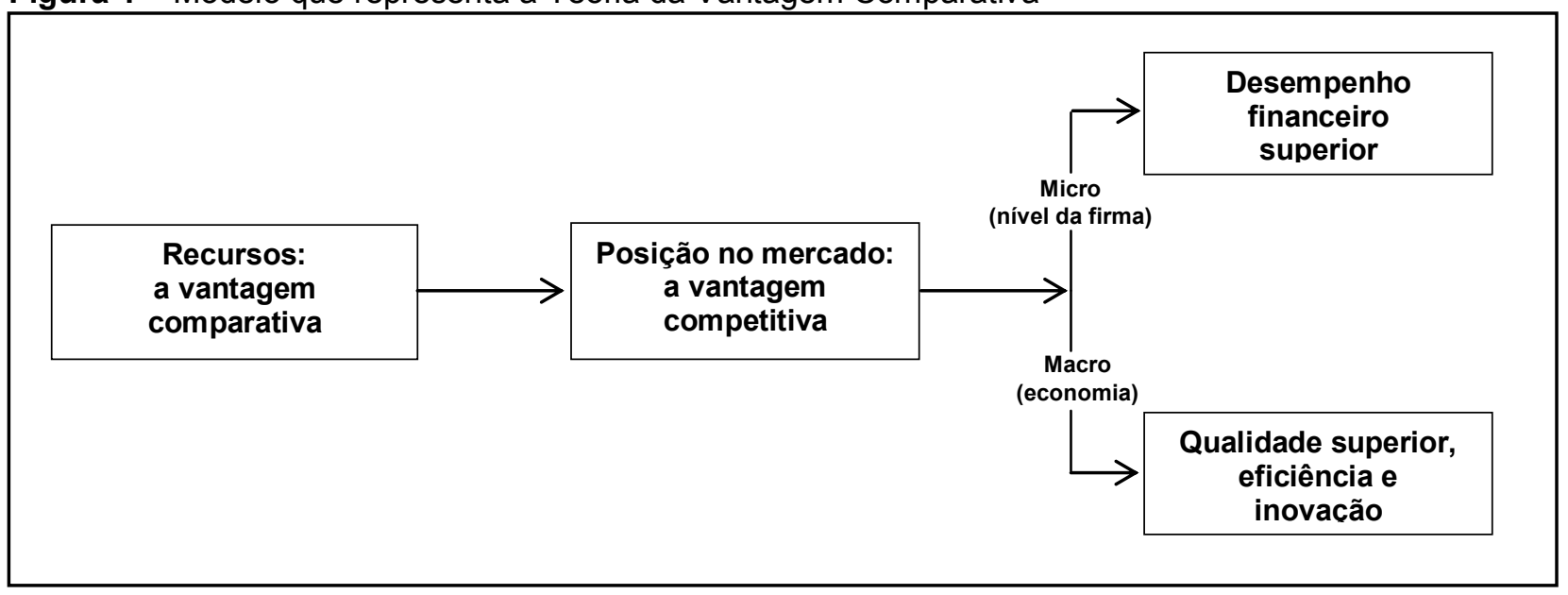

Fonte: Adaptado de Hunt e Morgan (1995).

Vale ressaltar que o sucesso de uma empresa está fundamentalmente associado à sua capacidade de gerar e de reter conhecimento, envolvida por um ambiente que contribui para a atividade de inovação. Evidentemente que, ao buscar tal inovação, a empresa age como um "risk taker", já que, sob condições de incerteza, corre-se o risco de seu novo projeto não dar certo, ou seja, seu novo produto pode não ser aceito ou não corresponder às expectativas de seus clientes. Por outro lado, tal mudança pode ser vista como algo de valor pelo seu público-alvo. É nestas condições que surge a possibilidade para o lucro e para a performance 
financeira superior, sendo este o prêmio pela inovação e pelo risco que o empresário está disposto a correr (CHRISTENSEN, 2011; CANONGIA et al., 2004).

Neste contexto, Hunt e Morgan (1995) apresentam as possíveis posições competitivas para uma empresa, relacionadas ao valor produzido pelos recursos e o custo relativo à produção de valor pelo recurso. Segundo os autores, sempre que possível, a empresa deverá preferir a posição competitiva que remeta a uma situação em que haverá uma vantagem comparativa em recursos capaz de produzir um valor superior a um custo baixo, proporcionando um retorno financeiro superior. Vale destacar que os recursos dizem respeito aos elementos tangíveis e intangíveis capazes de fazer com as empresas ofertem ao mercado, de maneira eficiente, algo que tenha valor para o setor, segmento ou nicho de mercado em que atuam (BARNEY, 1991; BESANKO et al., 2012; BARNEY; HESTERLY, 2011).

\subsection{A VBR - Visão Baseada em Recursos como Base para o Entendimento da Teoria da Vantagem Comparativa}

A oferta de tecnologia de fácil acesso cria a possibilidade da paridade tecnológica, dependente apenas de recursos financeiros. Isso, porém, não explica o diferencial competitivo das organizações. Com base na teoria da Visão Baseada em Recursos (VBR), "olha-se" para dentro das organizações com o entendimento de que empresas similares, com a mesma base tecnológica, podem apresentar desempenhos totalmente diferentes, dependendo das competências organizacionais que possuem. Isto significa que há formas diferentes de explorar e mobilizar recursos estratégicos e, consequentemente, níveis diferentes de entrega de valor aos clientes, os quais poderão proporcionar algum tipo de vantagem competitiva.

De fato, as empresas são diferentes entre si, já que nenhuma delas possui exatamente a mesma gama de recursos (financeiros, humanos, físicos e tecnológicos), uma vez que possuem diferentes ativos e características, desenvolvendo, ao longo do tempo, habilidades e competências únicas e criando a sua própria cultura organizacional (NETO; ALCANTARA, 2013). Neste horizonte, os pressupostos da VBR enfatizam que as diferenças entre as performances de empresas e, portanto, possíveis vantagens competitivas, são oriundas das 
características heterogêneas dos recursos e como eles são geridos. Tendo como origem os trabalhos de Penrose (1959), Wernefelt (1984) e Barney (1991), a VBR se propõe a analisar as organizações e seus sucessos estratégicos a partir dos seus recursos. Aliás, Fernandes, Fleury e Mills (2006) ressaltam que é preciso que tais recursos sejam mobilizados, coordenados e "entregues" para se garantir o desempenho organizacional desejado.

Isto posto, Barney (1991) define recursos como sendo todos os ativos, capacidades, processos organizacionais, atributos (características), informações e conhecimento que são controlados pela empresa, e que a habilitam a conceber e implementar estratégias que melhorem sua eficiência e eficácia. De acordo com Barney (1991), a sustentabilidade de uma possível vantagem competitiva presume quatro características dos recursos, as quais são, respectivamente:

a) Os recursos devem ser valiosos, permitindo que a empresa conceba e implemente estratégias eficientes, eficazes e efetivas;

b) Os recursos devem ser raros, fazendo com que a empresa tenha uma estratégia baseada na criação de valor sem que os competidores consigam implementá-la simultaneamente (pela falta destes recursos);

c) Os recursos devem ser de difícil imitabilidade, a qual ocorre quando há a combinação de três fatores: (i) a habilidade da empresa de obter recursos depende de sua trajetória histórica única; (ii) a relação entre os recursos possuídos pela empresa e a sua vantagem competitiva apresenta ambigüidade causal; e (iii) a geração de recursos é socialmente complexa;

d) Os recursos devem resistir à substituição quando outras empresas não conseguem implementar estratégia similar com recursos equivalentes.

Sendo assim, a VBR está vinculada à complexidade do movimento constante de reflexão e consolidação de estratégias e de práticas, e pressupõe que uma empresa é um portfólio de recursos humanos, físicos, financeiros, intangíveis, e organizacionais (BARNEY, 1991; WERNEFELT, 1984; 1995).

Uma vez que as empresa visam um desempenho financeiro superior, os competidores tentarão neutralizar o concorrente que possui uma vantagem comparativa, obtendo o mesmo valor produzido pelo recurso da empresa que está em vantagem no mercado. Se o recurso puder ser adquirido no mercado, a 
vantagem comparativa será neutralizada rapidamente. Se, por outro lado, o recurso não puder ser comprado, os competidores partirão para o processo de inovação (HUNT; MORGAN, 1995; ÖZSOMER; CALANTONE; DI BENEDETTO, 1997; HULT; HURLEY, 2004). Neste caso, o comportamento inovador será no sentido de imitar o recurso desejado ou de encontrar um recurso substituto estrategicamente equivalente (BARNEY, 1991).

Porém, é oportuno destacar que, enquanto neutralizar a vantagem de um competidor, por meio da imitação e da substituição de um recurso estratégico produz apenas uma paridade no retorno financeiro das empresas, identificar e obter um novo recurso pode resultar em uma posição de vantagem competitiva ou em retornos financeiros superiores (HUNT; MORGAN, 1995; PORTER, 1995). Dessa forma, a Teoria da Vantagem Comparativa e suas possíveis posições competitivas para as empresas são capazes de explicar porque economias baseadas no mercado são mais inovativas, já que a inovação é capaz de fornecer uma vantagem comparativa, que pode ser mantida ao longo do tempo, transformando-se em uma vantagem competitiva (HUNT; MORGAN, 1995; PORTER, 1995; DOZ; SANTOS; WILLIAMSON, 2004; BESANKO et al., 2012; HOSKISSON et al., 2009).

\subsection{A Inovação como Possível Fonte de Vantagem Competitiva}

A literatura sobre inovação tem em sua fundação as contribuições de Schumpeter e, em especial, sua tentativa de teorização sobre a relação entre inovação tecnológica e o desenvolvimento econômico. O crescimento da economia é visto como um processo dinâmico, e que depende, tanto da geração e uso das inovações, quanto dos processos de difusão das mesmas. Os avanços - produtivos, tecnológicos, organizacionais, etc. - resultantes de processos inovativos são tomados com fator básico na formação dos padrões de transformação da economia e de seu desenvolvimento a longo prazo (SCHUMPETER, 1912; 1942).

As constantes mudanças de mercado fazem com que as empresas lancem produtos e/ou serviços diferenciados ou inovadores, com o objetivo de ofertar algo de valor agregado aos seus clientes, buscando atingir um melhor desempenho para o negócio. Portanto, a inovação é um esforço intencional e disciplinado, e o tipo de 
estratégia e a estrutura organizacional exercem influência sobre as inovações de uma empresa (MENGUC; AUH, 2009). Os fatores que tornam as empresas inovadoras são geralmente complexos, uma vez que a postura estratégica, a estrutura organizacional e as incertezas do ambiente competitivo influenciam na capacidade inovadora das empresas (ÖZSOMER; CALANTONE; BONETTO, 1997).

As empresas realmente inovadoras são aquelas que conseguem explorar recursos disponíveis e vantagens competitivas difundidas no mundo dos negócios. Para tanto, devem reunir as "partes" do conhecimento que estão espalhadas e estabelecer uma forma de organização adequada para promover os seus esforços de inovação (DOZ; SANTOS; WILLIAMSON, 2004).

A inovação é um processo interativo, que pode ser dividido, em essência, em quatro etapas, que consistem em: (i) planejamento da inovação; (ii) desenvolvimento de tecnologias; (iii) desenvolvimento de produtos e/ou serviços; e (iv) lançamento destas ofertas no mercado (OLIVEIRA et al., 2011). Neste processo, as empresas, em interação umas com as outras, e apoiadas por diferentes organizações e instituições - associações industriais, centros de pesquisa e tecnológicos, organismos de normatização, centros de capacitação e aperfeiçoamento, órgãos de fomento, entre outras - desempenham um papel-chave, adequando novos produtos, novos processos e novas formas de organização (MITELKA; FARINELLI, 2005).

Kim e Mauborgne (1999), examinando a inovação em diversas empresas européias e norte-americanas, a definiram como uma nova forma de romper barreiras estabelecidas em um setor, criando soluções diferenciadas a baixo custo. Em confronto direto com a ideia de que a diferenciação e o baixo custo são posições estratégicas excludentes, estes autores defendem que inovação é a capacidade das empresas entenderem as necessidades comuns dos clientes, propondo soluções únicas que agreguem valor a eles. Já para Dosi (1988), a inovação diz respeito à descoberta, à experimentação, ao desenvolvimento, à imitação e à adoção de novos produtos, novos processos de produção ou novas formas organizacionais.

Ou seja, a estratégia da inovação é essencial para que as empresas sejam competitivas, lucrativas e rentáveis, por trabalhar as competências, a criatividade e a capacidade de verificar soluções alternativas (CANONGIA et al., 2004). A principal relação entre inovação e competitividade reside no fato de possibilitar a criação de 
novos produtos e/ou serviços e processos melhor ajustados (CHRISTENSEN, 2011; CHRISTENSEN et al., 2007). Dessa maneira, busca-se desenvolver todos os setores da empresa para que contribuam para o sucesso de um processo de inovação. Por conseguinte, a área comercial precisa estar em sintonia com a área de desenvolvimento de produtos e/ou serviços, para que tenha os mecanismos e os recursos adequados quando for vender estes novos produtos e/ou serviços (HUERGO, 2006).

Vale destacar, ainda, que as economias baseadas em mercado promovem um fluxo de recompensa às empresas e aos indivíduos que desenvolvem produtos e processos inovativos. Inovações revolucionárias podem oferecer ao inovador vantagens comparativas que podem ser mantidas ao longo do tempo. Além disso, pequenas inovações realizadas ao longo do tempo têm efeito cumulativo sobre os seus recursos e, então, sobre sua eficiência, eficácia e efetividade. Sendo assim, uma qualidade superior, diferenciada, acaba sendo uma consequência do aprimoramento constante dos produtos e/ou serviços e dos processos de uma empresa realizados por meio das inovações (HUNT; MORGAN, 1995).

Nesta direção, de acordo com o estudo de De Negri e Suszigan (2005), quando uma empresa busca inovação tecnológica, tem como meta principal melhorar recursos e potencialidades da organização, garantindo, assim, vantagens comparativas ou, se possível, vantagens competitivas, que devem se transformar em aumento da lucratividade e da rentabilidade. Isso ocorre porque produtos e/ou serviços altamente inovadores possibilitam que a empresa evite a concorrência pelo preço, ou melhor, por preços baixos (ROSENBUSCH; BRINCKMANN; BAUSCH, 2011).

Além disso, conforme Kim e Maubourgne (2005), para garantir a sobrevivência e manter-se competitivo em mercados internacionais, é incontestável a necessidade das empresas investirem em inovação. Dessa forma, a inovação emerge como um recurso fundamental para o enquadramento da empresa às normas ou às exigências do mercado externo e também para a abertura de novos mercados (GORODNICHENKO; SVEJNAR; TERRELL, 2010).

Por fim, um reforço positivo aos esforços de inovação diz respeito ao fato da mesma influenciar diretamente no bem estar social, já que os benefícios humanos e 
a função social das empresas faz parte dos resultados do processo de inovação, especialmente daquelas que se beneficiam de recursos públicos (QUINELLO, 2009)

\subsection{Alguns Indicadores de Desempenho Financeiro Relevantes às Empresas}

A análise do desempenho financeiro das empresas pode se utilizar de diversos indicadores, entretanto, foram abordados os indicadores utilizados no presente estudo e que correspondem ao nível micro de análise resultantes do modelo de Hunt e Morgan (1995) (vide Figura 1). Dessa forma, dentre os possíveis indicadores que mensuram o desempenho financeiro das empresas, são apresentados os seguintes: o ROE - Return on Equity (Retorno sobre o Patrimônio Líquido), o ROA - Return on Assets (Retorno sobre os Ativos) e o ROS - Return on Sales (Retorno sobre as Vendas). Conforme Assaf Neto (2012), estes indicadores representam uma avaliação adequada do desempenho de uma empresa, dimensionando o retorno sobre os investimentos realizados e sobre as suas vendas.

\subsubsection{ROE - Return on Equity (Retorno sobre o Patrimônio Líquido)}

O primeiro deles, o ROE, mensura o retorno dos recursos aplicados na empresa pelos sócios ou investidores. Na visão de Dutzig (2002), o indicador representa a taxa de rentabilidade obtida pelo capital próprio da empresa, sendo equacionado pela relação entre o lucro líquido e o patrimônio líquido da mesma. Assim sendo, o ROE pode ser calculado da seguinte forma:

\section{ROE = Lucro Líquido / Patrimônio Líquido}

A vantagem do ROE é que este indicador expressa os resultados globais auferidos na gestão dos recursos próprios e de terceiros em benefício do proprietário, acionista ou investidor da empresa (IUDÍCIBUS, 2010). Salienta-se que, segundo Franco (1989), o lucro líquido é produzido não apenas pelo capital próprio, mas também pelo capital de terceiros empregado no negócio, destacando a importância do ROE. 


\subsubsection{ROA - Return on Assets (Retorno sobre os Ativos)}

O ROA afere o retorno produzido pelo total do capital empregado pela empresa em seus ativos. Segundo Matarazzo (2010), este indicador apresenta a medida do potencial de geração de lucro do negócio, não como rentabilidade, mas como medida da capacidade de gerar lucro líquido e, desse modo, poder capitalizarse. O ROA é equacionado a partir da seguinte fórmula:

$$
\text { ROA = Lucro Líquido / Ativo Total }
$$

Franco (1989) destaca a relação deste indicador com a rotação do capital da empresa, ou seja, o giro do ativo. Neste sentido, cita o exemplo de que, quando a porcentagem de lucro sobre as receitas (vendas) é baixa, tal questão pode ser compensada pelo elevado quociente de rotação do ativo, fazendo com que o resultado em relação ao investimento realizado possa ser satisfatório. Uma maior rotatividade do ativo beneficia, então, a rentabilidade do capital próprio.

\subsubsection{ROS - Return on Sales (Retorno sobre as Vendas)}

Por sua vez, o ROS mede a eficiência da empresa em produzir lucro por meio de suas vendas. O ROS mensura o percentual de lucro líquido auferido sobre o total das vendas (MARION, 2012). Por conseguinte, é equacionado da seguinte forma:

$$
\text { ROS = Lucro Líquido / Vendas Brutas }
$$

Um baixo ou elevado nível de ROS está relacionado às características da empresa e do seu mercado de atuação. Alguns segmentos de mercado atuam com elevado valor (volume) de vendas, porém, com margens pequenas. Outros podem ter baixo valor (volume) de vendas, mas com margens elevadas (IUDíCIBUS, 2010). 


\section{MÉTODO DE PESQUISA}

Para a elaboração do estudo, foi acessado o banco de dados Economática Software para Investimentos, coletando-se as informações de ROE, ROA e ROS, relativas aos exercícios de 2006 a 2010, das empresas negociadas na BOVESPA (Bolsa de Valores de São Paulo - SP). Foram descartadas da amostra as empresas que tiveram a abertura de capital posterior à 01/01/2006, bem como as empresas que deixaram de ser negociadas no período avaliado. Também foram descartadas as empresas com patrimônio líquido negativo e que apresentaram vendas líquidas nulas no período avaliado, dado que, nestes casos, não é possível calcular os indicadores escolhidos.

Como critério para avaliar as inovações apresentadas pelas empresas no período, foi utilizado o número de patentes registradas. Tais informações foram acessadas pelo site do INPI. Segundo a definição do INPI (2012), "patente é um título de propriedade temporária sobre uma invenção ou modelo de utilidade, outorgado pelo Estado aos inventores ou autores ou outras pessoas físicas ou jurídicas detentoras de direitos sobre a criação". As patentes são tipificadas em: patentes de invenção, modelo de utilidade e certificado de adição de invenção. As patentes de invenção consistem em produtos ou processos que caracterizem invenção, novidade e com aplicação industrial. O modelo de utilidade, basicamente, diz respeito ao objeto de uso prático que apresente nova forma, envolvendo ato inventivo e que seja suscetível à aplicação industrial. Por fim, o certificado de adição de invenção, que compreende melhorias introduzidas no objeto da invenção, segundo o mesmo conceito inventivo (INPI, 2012).

A Tabela 1 apresenta as empresas que integram a amostra da pesquisa, o setor ao qual pertencem e o número de inovações de cada uma delas no período. 
Tabela 1 - Empresas, setores de atuação e número de patentes depositadas entre 2006 e 2010

\begin{tabular}{|c|c|c|c|c|c|}
\hline Empresas & Setores & Patentes & Empresas & Setores & Patentes \\
\hline AES Elpa & Energia elétrica & 0 & Guararapes & Têxtil & 0 \\
\hline Alfa Investimentos & Finanças e seguros & 0 & Indústrias Romi & Máquinas industriais & 0 \\
\hline All América Latina & Serviços de transporte & 0 & Inepar & Outros & 0 \\
\hline Alpargatas & Têxtil & 18 & Itausa & Outros & 0 \\
\hline AmBev & Alimentos e bebidas & 0 & Itautec & Eletroeletrônicos & 13 \\
\hline Ampla Energ. & Energia elétrica & 1 & Itaú/Unibanco & Finanças e seguros & 0 \\
\hline Banese & Finanças e Seguros & 0 & Jereissati & Outros & 0 \\
\hline Bardella & Máquinas industriais & 0 & João Fortes & Construção & 0 \\
\hline Bradesco & Finanças e seguros & 3 & Klabin & Papel e celulose & 7 \\
\hline Bradespar & Outros & 0 & Light & Energia elétrica & 7 \\
\hline Brasil & Finanças e seguros & 0 & Localiza & Outros & 0 \\
\hline Brasil Telecom. & Telecomunicações & 1 & Lojas Americanas & Comércio & 0 \\
\hline Braskem & Química & 49 & Lojas Renner & Comércio & 0 \\
\hline CCR AS & Serviços de transporte & 1 & Mangels & Siderurgia e metalurgia & 0 \\
\hline Celesc & Energia elétrica & 1 & Marcopolo & Veículos e peças & 24 \\
\hline Celpa & Energia elétrica & 0 & Metal Leve & Veículos e peças & 15 \\
\hline Cemar & Energia elétrica & 3 & Metisa & Siderurgia e metalurgia & 3 \\
\hline Cemat & Energia elétrica & 0 & Mundial & Siderurgia e metalurgia & 4 \\
\hline Cemig & Energia elétrica & 14 & Natura & Comércio & 17 \\
\hline Coelce & Energia elétrica & 0 & Net & Outros & 0 \\
\hline Comgás & Petróleo e gás & 1 & OHL Brasil & Serviços de transporte & 0 \\
\hline Confab & Siderurgia e metalurgia & 0 & Pão de Açúcar/CBD & Comércio & 0 \\
\hline Contax & Outros & 0 & Petrobras & Petróleo e gás & 325 \\
\hline Copel & Energia elétrica & 1 & Porto Seguro & Finanças e seguros & 6 \\
\hline Cosan & Alimentos e bebidas & 0 & Randon Part. & Veículos e peças & 37 \\
\hline CPFL Energia & Energia alétrica & 11 & Rossi Resid. & Construção & 0 \\
\hline Cyrela Realty & Construção & 0 & Sabesp & Outros & 0 \\
\hline Dasa & Outros & 0 & Sanepar & Outros & 0 \\
\hline Dohler & Têxtil & 0 & Saraiva Livraria & Outros & 0 \\
\hline Eletrobras & Energia elétrica & 0 & Siderúrgica Nacional & Siderurgia e metalurgia & 16 \\
\hline Embraer & Veículos e peças & 37 & Souza Cruz & Outros & 9 \\
\hline Embratel Partic. & Telecomunicações & 0 & Suzano Papel & Papel e celulose & 5 \\
\hline Energias BR & Energia elétrica & 0 & Tam & Serviços de transporte & 0 \\
\hline Energisa & Energia elétrica & 2 & Tekno & Siderurgia e metalurgia & 1 \\
\hline Eternit & Minerais não-metais & 4 & Telefônica Brasil & Telecomunicações & 0 \\
\hline Ferbasa & Siderurgia e metalurgia & 0 & Telemar & Telecomunicações & 0 \\
\hline Fibam & Siderurgia e metalurgia & 0 & Telemar N L & Telecomunicações & 0 \\
\hline Forjas Taurus & Siderurgia e metalurgia & 0 & Tim Participações & Telecomunicações & 0 \\
\hline Ger Paranapanema & Energia elétrica & 0 & Tractebel & Energia elétrica & 0 \\
\hline Gerdau & Siderurgia e metalurgia & 13 & Tran Paulist & Energia elétrica & 0 \\
\hline Gol & Serviços de transporte & 0 & Ultrapar & Química & 0 \\
\hline Grazziotin & Comércio & 0 & Usiminas & Siderurgia e metalurgia & 44 \\
\hline Grendene & Têxtil & 23 & Vale & Mineração & 31 \\
\hline
\end{tabular}

Fonte: Elaborada pelos autores a partir dos dados disponibilizados por Economática e INPI (2012).

Revista Produção Online, Florianópolis, SC, v.14, n. 1, p. 58-83, jan./mar. 2014. 
Com base nestes dados, as 86 empresas foram separadas em dois grupos. O primeiro grupo, denominado "Sem Inovação", que contemplou todas as empresas que não registraram patentes no período (2006 a 2010). O segundo grupo, denominado "Inovadoras", contemplou as empresas que apresentaram pelo menos um registro de patente no período. O grupo das empresas "Sem Inovação" totalizou 52 empresas, enquanto que o grupo das empresas "Inovadoras", 34 empresas.

Procedeu-se, então, a análise dos indicadores de desempenho financeiro (ROE, ROA e ROS) para os dois grupos de empresas, utilizando-se a média dos exercícios de 2006 a 2010 de cada uma das 86 empresas avaliadas. Em um primeiro momento, os indicadores dos dois diferentes grupos foram comparados a partir de estatística descritiva (HAIR Jr. et al., 2007; REMLER; VAN RYZIN, 2011). Nesta comparação, verificou-se os valores mínimo, máximo e médio, bem como o desvio padrão, de cada um dos indicadores de performance (ROE, ROA e ROS) para cada um dos dois grupos.

Posteriormente, para avaliar a existência de diferença de performance (ROE, ROA e ROS) entre os dois grupos, utilizou-se a regressão linear múltipla. Optou-se pela utilização desta técnica, uma vez que a mesma é indicada quando o objetivo é analisar os efeitos de variáveis independentes sobre uma variável dependente (HAIR Jr. et al., 2007). De modo semelhante, Johnson e Wichern (2007) e Afifi, May e Clark (2012) afirmam que o objetivo da regressão linear é desenvolver uma equação que permita explicar a variável de resposta (variável dependente), tomando valores fornecidos para as variáveis independentes.

No intuito de observar se os dois grupos ("Sem Inovação" e "Inovadoras") apresentam diferenças significativas em relação ao seu desempenho financeiro, foram utilizadas como variáveis dependentes os indicadores ROE, ROA e ROS, capturados do software Economática, conforme descrito anteriormente. Como variável independente, foi introduzida uma variável dummy para as empresas do grupo das "Inovadoras". Conforme Malhotra (2009), as variáveis dummies são variáveis de ordem nominal ou categórica que podem ser usadas como variáveis prognosticadoras independentes. Assim, admitiu-se como variável independente o valor de 1 (um) para as empresas do grupo "inovadoras" e o valor de 0 (zero) para o grupo das empresas "sem inovação". 
Sendo assim, os modelos de regressão apresentaram a dependência dos indicadores de performance (ROE, ROA e ROS) em relação ao fato de serem consideradas empresas "Inovadoras" ou "sem inovação". O procedimento proposto pode ser expresso na equação a seguir, que apresenta um modelo explicativo para a previsão do indicador de performance em função do grupo de empresas ("inovadoras" ou "sem inovação"):

$$
\mathrm{RO}=\mathrm{a}+\mathrm{b}_{2} \mathrm{D}_{2}+\mathrm{E}
$$

Onde:

RO: desempenho financeiro esperado (rentabilidade) para a empresa - ROE, ROA ou ROS;

a: coeficiente linear esperado para o indicador;

$\mathrm{b}_{2}$ : diferença no desempenho (performance) esperado para as empresas pertencentes ao grupo das empresas "Inovadoras";

$\mathrm{D}_{2}$ : variável dummy para o grupo de empresas (1, se empresas "Inovadoras" e 0, se "Sem Inovação")

E: resíduo aleatório

Para avaliar se o modelo de regressão é válido, investigou-se a significância do teste F, que, de acordo com Pestana e Gageiro (2008), deve apresentar um nível inferior a 0,05 . Se, ao avaliar o modelo de regressão, observa-se uma significância inferior a 0,05 , pelo menos um coeficiente da regressão é diferente de zero.

$\mathrm{Na}$ sequencia, para verificar quais dos coeficientes, em específico, devem ser considerados ou descartados, avalia-se o valor-P, que, do mesmo modo, necessita ser inferior a 0,05 para o coeficiente ser considerado como relevante (MALHOTRA, 2009). Por outro lado, se o coeficiente angular apresentar um nível de significância superior a 0,05, aceita-se a hipótese de igualdade entre os indicadores de performance dos dois grupos ("inovadoras" e "sem inovação"). Porém, se o nível de significância for inferior a 0,05 , rejeita-se a igualdade entre os indicadores dos dois grupos de empresas. 


\section{ANÁLISE DOS RESULTADOS}

A seguir, são apresentados os resultados da análise dos dados para cada um dos indicadores de desempenho financeiro considerados.

\subsection{ROE - Return on Equity (Retorno sobre o Patrimônio Líquido)}

Com o intuito de visualizar o comportamento do ROE das empresas avaliadas, segundo os grupos "Sem Inovação" e "Inovadoras", é apresentada a Tabela 2, que mostra os dados de estatística descritiva do indicador. Observa-se que a média do ROE das empresas "Sem Inovação" é de 18,89\%, enquanto que as empresas "Inovadoras" apresentam uma média de ROE de 25,68\%.

Tabela 2 - Estatística descritiva - ROE

\begin{tabular}{cccccc}
\hline Grupos & Empresas & Mínimo & Máximo & Média & Desvio-Padrão \\
Sem Inovação & 52 & $1,74 \%$ & $48,70 \%$ & $18,89 \%$ & 11,37 \\
Inovadoras & 34 & $2,84 \%$ & $80,04 \%$ & $25,68 \%$ & 15,40 \\
\hline
\end{tabular}

Fonte: Dados provenientes da análise dos dados.

Os cálculos de regressão linear foram aplicados levando em conta o ROE como variável dependente e a variável dummy relativa ao grupo das empresas "Inovadoras" como variável independente. O valor de explicação do R-quadrado ajustado foi de 5,05\%. A significância do teste $F$ do modelo foi de 0,0211 .

Tabela 3 - Testes de regressão - ROE

\begin{tabular}{c|c|c|c|c} 
& Coeficientes & Erro padrão & Stat t & valor-P \\
\hline Interseção & 18,8903 & 1,8168 & 10,3973 & 0,0000 \\
\hline Inovação & 6,7910 & 2,8895 & 2,3502 & 0,0211 \\
\hline
\end{tabular}

Fonte: Dados provenientes da análise dos dados.

O coeficiente linear do modelo foi de 18,89 , com valor-P de 0,0000 , enquanto que o coeficiente relativo à variável dummy foi de 6,79, com valor-P de 0,0211. Assim, com um nível de significância de 5\%, aceita-se que o grupo das empresas "Inovadoras" possui ROE superior ao grupo das empresas "Sem Inovação". 


\subsection{ROA - Return on Assets (Retorno sobre os Ativos)}

A Tabela 4 apresenta os dados da estatística descritiva do indicador ROA. É possível visualizar que o ROA médio entre as empresas "Sem Inovação" foi de $5,33 \%$ e que, para as empresas "Inovadoras", $8,70 \%$.

Tabela 4 - Estatística Descritiva - ROA

\begin{tabular}{c|c|c|c|c|c}
\hline Grupos & Empresas & Mínimo & Máximo & Média & Desvio-Padrão \\
\hline Sem Inovação & 52 & $0,88 \%$ & $13,62 \%$ & $5,33 \%$ & 3,83 \\
\hline Inovadoras & 34 & $0,26 \%$ & $29,40 \%$ & $8,70 \%$ & 6,08 \\
\hline
\end{tabular}

Fonte: Dados provenientes da análise dos dados.

A partir disso, chegou-se a um modelo de regressão linear, considerando os valores de ROA como variável dependente e a variável dummy relativa ao grupo das empresas "Inovadoras" como variável independente. O modelo demonstrou-se estatisticamente significativo, com significância do teste $F$ de 0,0022 e valor de explicação do R-quadrado ajustado de $4,84 \%$.

Tabela 5 - Testes de regressão - ROE

\begin{tabular}{c|c|c|c|c} 
& Coeficientes & Erro padrão & Stat t & valor-P \\
\hline Interseção & 5,3292 & 0,6714 & 7,9378 & 0,0000 \\
\hline Inovação & 3,3725 & 1,0678 & 3,1585 & 0,0022 \\
\hline
\end{tabular}

Fonte: Dados provenientes da análise dos dados.

A regressão demonstrou um coeficiente linear de 5,32, com valor-P de 0,0000 . Já o coeficiente relacionado à variável dummy foi de 3,37 , com valor-P de 0,0022 . Os resultados da regressão linear confirmam que é possível aceitar estatisticamente que o grupo das empresas "Inovadoras" apresenta um ROE superior ao grupo das empresas "Sem Inovação".

\subsection{ROS - Return on Sales (Retorno sobre as Vendas)}

Os dados da estatística descritiva provenientes do indicador ROS são apresentados na Tabela 6. A partir destes dados, verifica-se que a média do ROS das empresas "Inovadoras", com 12,59\%, é superior ao das empresas "Sem Inovação", que resultou em 10,76\%. 
Tabela 6 - Estatística Descritiva - ROS

\begin{tabular}{c|c|c|c|c|c}
\hline Grupos & Empresas & Mínimo & Máximo & Média & Desvio-Padrão \\
\hline Sem Inovação & 52 & 1,64 & 38,06 & 10,76 & 8,62 \\
\hline Inovadoras & 34 & 0,54 & 29,60 & 12,59 & 6,72 \\
\hline
\end{tabular}

Fonte: Dados provenientes da análise dos dados.

Foi elaborado, então, o modelo de regressão linear, no qual a variável dependente considerada foi o ROS e a variável independente foi a variável dummy relativa ao grupo das empresas "Inovadoras". O modelo apresentou um R-quadrado ajustado de $0,0011 \%$ e significância do teste $F$ de 0,2975 , o que demonstra que o modelo não é significativo estatisticamente.

Tabela 7 - Testes de regressão - ROS

\begin{tabular}{c|c|c|c|c} 
& Coeficientes & Erro padrão & Stat t & valor-P \\
\hline Interseção & 10,7573 & 1,0993 & 9,7853 & 0,0000 \\
\hline Inovação & 1,8327 & 1,7484 & 1,0482 & 0,2975 \\
\hline
\end{tabular}

Fonte: Dados provenientes da análise dos dados.

O modelo de regressão apontou um coeficiente linear de 10,75, com valor-P de 0,0000 , considerado estatisticamente significativo. No entanto, o coeficiente relacionado à variável dummy, de 1,83, teve valor-P de 0,2975. Assim, apesar de o coeficiente linear ser considerado estatisticamente significativo, o coeficiente angular demonstrou-se não significativo. Com isso, rejeita-se que o grupo das empresas “Inovadoras” possui um ROS superior ao grupo das empresas "Sem Inovação”.

\section{DISCUSSÃO SOBRE OS RESULTADOS}

Os resultados provenientes da análise dos dados mostraram que as empresas com perfil inovador são capazes de obter rentabilidade superior. Apesar de não apresentarem resultados estatisticamente significativos para o ROS, os resultados da análise dos indicadores ROE e ROA demonstraram diferença entre os grupos das empresas "Inovadoras" e "Sem Inovação". Esta observação reforça a ideia de que as empresas que promovem esforços de inovação são capazes de, ao empregar seus recursos para o desenvolvimento de novos produtos e/ou serviços e processos, podem obter uma posição de vantagem comparativa sobre os 
concorrentes, repercutindo em retornos financeiros superiores (HUNT; MORGAN, 1995; AMIT; SCHOEMAKER, 1993; HULT; HURLEY, 2004; MENGUC; AUH, 2009).

O cálculo do indicador ROE demonstrou que o grupo das empresas "Inovadoras" possui rentabilidade superior às empresas "Sem Inovação". Enquanto o grupo das empresas "Sem Inovação" apresentou ROE médio de 18,89\%, as empresas "Inovadoras" obtiveram ROE de 25,68\%. A diferença de 6,79\% entre os dois grupos equivale a uma rentabilidade $35,94 \%$ superior do grupo das empresas "Inovadoras".

As análises do indicador ROA apresentaram os mesmos resultados obtidos no indicador ROE. As empresas "Sem Inovação" obtiveram um ROA médio de $5,33 \%$ e as empresas "Inovadoras" de 8,70\%. A diferença entre os dois grupos foi de $3,37 \%$, o que equivale a uma rentabilidade $63,23 \%$ superior para o grupo das empresas "Inovadoras".

Já a análise do ROS não comprovou diferença estatisticamente significativa entre os dois grupos, embora a média do ROS das empresas "Inovadoras" tenha sido superior à média das empresas "Sem Inovação". O grupo das empresas "Inovadoras" apresentou um ROS médio de 10,76\%, enquanto que o grupo das empresas "Sem Inovação" obteve um ROS médio de 12,59\%. O coeficiente de $1,83 \%$, equivalente à diferença entre os grupos, não foi estatisticamente significativo. Isto está em desacordo com o que é postulado por Ricardo (1996), já que o autor afirma que ao inovar ou "fazer algo diferente" a empresa será capaz de gerar uma curva de produção diferente, possibilitando a redução de custos e/ou vendas com maiores margens de lucro.

A explicação mais provável para o fato da diferença no ROS não ter sido considerada estatisticamente significativa está relacionada ao fato de que o estudo em questão avaliou empresas de diversos segmentos, que acabam apresentando diferentes níveis de ROS, tendo em vista as especificidades de suas ofertas e de seus mercados de atuação. Segundo salientado por ludícibus (2010), o alto ou baixo nível de ROS está relacionado ao segmento em que a empresa atua, sendo que, em alguns segmentos, as empresas atuam com elevado valor (volume) de vendas e margens reduzidas, enquanto em outros, atuam com baixo valor (volume) de vendas e margens mais elevadas. Em função de que o presente estudo avaliou empresas 
de segmentos diversos, tal questão pode ter impactado para que a diferença de ROS entre os dois grupos não tenha sido significativa.

De toda forma, a diferença estatisticamente significativa nos indicadores ROE e ROA dão suporte ao argumento de que o grupo das empresas "Inovadoras" atuam com rentabilidade superior ao grupo das empresas que não apresentam inovação. Dessa forma, verificou-se que, uma vez que as empresas sejam capazes de gerar valor por meio da conversão de seus recursos em atividades de inovação, ela será capaz de obter uma vantagem comparativa e, até mesmo, competitiva, em relação aos concorrentes, possibilitando resultados mercadológicos e financeiros superiores (PORTER, 1985; HUNT; MORGAN, 1995; HOOLEY; PIERCY; NICOLAUD, 2011).

\section{CONSIDERAÇÕES FINAIS}

No atual mercado competitivo, as empresas cumprem um papel de suma importância, reunindo e investindo seus recursos para realizar a produção, agregando valor a matérias-primas e materiais diversos neste processo. Além disso, vale destacar que, quanto maior a especificidade dos ativos, menor será a preocupação da empresa com a redução de custos, já que a especificidade do ativo aumenta a probabilidade deste ser a solução ótima e diferenciadora de mercado.

$E$, frente a isso, a inovação, um dos elementos geradores de possíveis vantagens competitivas sustentáveis, tem sido tema recorrente, pois a competição global tem dificultado sobremaneira as tentativas de sobrevivência em que não haja a presença de um diferencial competitivo. Este diferencial competitivo muitas vezes é gerado por uma inovação que, por meio do emprego dos recursos das empresas, exploram uma mudança ou uma oportunidade de mercado, oferecendo um novo produto e/ou serviço ao seu público-alvo (PORTER, 1985; DRUCKER, 1987; BARNEY, 1991; HULT; HURLEY, 2004; CHRISTENSEN et al., 2007).

Neste sentido, a principal contribuição deste estudo está relacionada ao fato de que os resultados apresentados suportam o argumento de que as empresas que promovem esforços de inovação apresentam um desempenho financeiro superior às empresas que não fazem investimentos nesta área, ao menos no que diz respeito aos indicadores relativos ao ROE e ROA. Dessa forma, por meio dos achados de 
pesquisa, foi possível observar que o desenvolvimento de recursos que garantam uma posição de vantagem comparativa às empresas permite que a mesma obtenha uma vantagem competitiva, a qual resultará na geração de inovações e, finalmente, em performance financeira superior, conforme defendido por Hunt e Morgan (1995). Gerencialmente, o estudo pode ser entendido como uma forma de validar e ampliar as iniciativas de gestores que visem desenvolver e fomentar a criação de recursos raros, valiosos, de difícil imitabilidade e substituição, para que, ao inovar, a empresa possa ter atrelado a isso uma rentabilidade superior aos competidores.

Como limitações do estudo, salienta-se que foram consideradas apenas empresas de capital aberto, uma vez que os dados destas empresas encontram-se disponíveis por meio do banco de dados Economática. Dessa forma, as empresas de capital fechado, em função da dificuldade de se obter seus dados contábeis, foram excluídas da pesquisa. Outra limitação diz respeito à análise ter sido realizada com um único grupo de empresas, sendo que no mesmo grupo havia empresas de diversos setores. Esta questão faz com que possa existir diferença nos indicadores das empresas de diferentes setores, dado que alguns setores atuam com margens mais elevadas do que outros. No entanto, cabe salientar que a listagem de empresas de capital aberto no Brasil não apresenta uma quantidade tão elevada de empresas como a do mercado norte-americano, por exemplo, dificultando a realização do estudo segmentado por setores de atuação das mesmas.

Por fim, sugere-se que estudos futuros sejam desenvolvidos no intuito de ampliar a avaliação dos indicadores de desempenho financeiro, explorando, por exemplo, elementos relativos aos indicadores de criação de valor ao acionista. Além disso, outros estudos podem ser realizados sobre esta temática, avaliando a inovatividade das empresas por meio de indicadores que remetam ao valor investido no processo de P,D\&I - Pesquisa, Desenvolvimento \& Inovação.

\section{REFERÊNCIAS}

AFIFI, A.; MAY, S.; CLARK, V. A. Practical multivariate analysis. $5^{\text {th }}$ edition. Boca Raton: Taylor \& Francis Group, 2012.

AMIT, R.; SCHOEMAKER, P. J. H. Strategic assets and organizational rent.

Strategic Management Journal, v. 14, n. 1, p. 33-46, 1993. 
ASSAF NETO, A. Finanças corporativas e valor. 6. ed. São Paulo: Atlas, 2012. BARNEY, J. B. Firm resources and sustained competitive advantage. Journal of Management, v. 17, n. 1, p. 99-120, 1991.

BARNEY, J. B; HESTERLY, W. Administração estratégica e vantagem competitiva: conceitos e casos. Pearson, 2011.

BESANKO, D.; DRANOVE, D.; SHANLEY, M.; SCHAEFER, S. A economia da estratégia. 5. ed. Porto Alegre: Bookman, 2012.

CANONGIA, C.; SANTOS, D. M.; SANTOS, M. M.; ZACKIEWICZ, M. Foresight, inteligência competitiva e gestão do conhecimento: instrumentos para a gestão da inovação. Gestão da Produção, v. 11, n. 2, p. 231-238, 2004.

CHRISTENSEN, C. The innovator's dilemma. New York: Harperbusiness, 2011.

CHRISTENSEN, C.; ANTHONY, S.; BERSTELL, G.; NITTERHOUSE, D. Finding the right job for your product. MIT Sloan Management Review, v. 8, n. 3, p. 38-47, 2007.

DE NEGRI, J.A.; SUSZIGAN, W. Competitive behavior in Brazilian industry: retrospect and prospects. In: DE NEGRI, J. A.; ARAÚJO, B. C. (Eds.).

Technological innovation in Brazilian and Mexican firms. Brasília: Ipea, 2009.

DOSI, G. The nature of the innovative process. In: DOSI, G. et al (Eds.). Technical change and economic theory. London: Pinter Publishers, 1988.

DRUCKER, P. Inovação e espírito empreendedor. 3. ed. São Paulo: Pioneira, 1987.

DOZ, Y.; SANTOS, J.; WILLIAMSON, P. Diversity: the key to innovation advantage. European Business Forum, v. 17, p. 25-27, 2004.

DUTZIG, J. B. A importância da análise das demonstrações financeiras na concessão de crédito. Taquara: FACCAT, 2002.

FERNANDES, B. H. R.; FLEURY, M. T. L.; MILLS, J. Construindo o diálogo entre competência, recursos e desempenho organizacional. Revista de Administração de Empresas, v. 46, n. 4, p. 48-65, 2006.

FRANCO, H. Estrutura, análise e interpretação de balanços: de acordo com a Lei das S/A., Lei n. 6.404, de 15-12-1976. 15. ed. São Paulo: Atlas, 1989.

GORODNICHENKO, Y.; SVEJNAR, J.; TERRELL, K. Globalization and innovation in emerging markets. American Economic Journal - Macroeconomics, v. 2, n. 2, p. 194-226, 2010. 
HAIR Jr., J. F.; ANDERSON, R. E.; TATHAM, R. L.; BLACK, W. C. Análise multivariada de dados. 6. ed. Porto Alegre: Bookman, 2007.

HOOLEY, G.; PIERCY, N. F.; NICOLAUD, B. Estratégia de marketing e posicionamento competitivo. 4. ed. São Paulo: Pearson, 2011.

HOSKISSON. R. E.; HITT, M. A.; IRELAND, R.D.; HARRISON, J. S. Estratégia competitiva. São Paulo: Cengage Learning, 2009.

HUNT, S. D.; MORGAN, R. M. The comparative advantage theory of competition. Journal of Marketing, v. 59, n. 2, p. 1-15, 1995.

HULT, G. T. M.; HURLEY, R. F.; KNIGHT, G. A. Innovativeness: its antecedents and impact on business performance. Industrial Marketing Management, v. 33, n. 5, p. 429-438, 2004.

HUERGO, E. The role os technological management as a source of innovation: Evidence from Spanish manufacturing firms. Research Policy, v. 35, n. 9, p.1.3771.388, 2006.

INPI - Instituto Nacional da Propriedade Intelectual. Site institucional. Disponível em: http://www.inpi.gov.br. Acesso em: 02 fev. 2012.

IUDÍCIBUS, S. Análise de balanços. 10. ed. São Paulo: Atlas, 2010.

JOHNSON, R. A.; WICKERN, D. W. Applied multivariate statistical analysis. $6^{\text {th }}$ edition. Upper Saddle River: Pearson / Prentice Hall, 2007.

KIM, C.; MAUBORGNE, R. Creating new market space. In: Harvard Business Review on Breakthrough Thinking. Harvard Business School Press: Boston, p.189-217, 1999.

KNIGHT, F. Risco, incerteza e lucro. Rio de Janeiro: Expressão e Cultura, 1972.

MALHOTRA, N. K. Marketing research: an applied orientation. $6^{\text {th }}$ edition. New Jersey: Prentice Hall, 2009.

MARION, J. C. Contabilidade empresarial. 16. ed. São Paulo: Atlas, 2012.

MATARAZZO, D. C. Análise financeira de balanços: abordagem básica e gerencial. 7. ed. São Paulo: Atlas, 2010.

MENGUC, B.; AUH, S. Development and return on execution of product innovation capabilities: the role of organizational structure. Industrial Marketing Management, v, 39, n. 5, p. 820-831, 2009. 
MITELKA, L.; FARINELLI, F. De aglomerados locais a sistemas de inovação. In: LASTRES, H. M. M.; CASSIOLATO, J. E.; ARROIO, A. (Eds.). Conhecimento, sistemas de inovação e desenvolvimento. Rio de Janeiro: Editora UFRJ, 2005.

NETO, J. S.; ALCANTARA, R. C. Competências essenciais presentes em frigoríficos brasileiros exportadores para Europa: um estudo multicaso. Revista Produção Online, v. 13, n. 1, p. 180-207, 2013.

OLIVEIRA, M. G.; PHAAL, D. P.; CUNHA, V. P.; ROZENFELD, H. A starting point for addressing product innovativeness in the fuzzy front-end. International Journal of Technology Intelligence and Planning, v. 7, n. 4, p. 309-326, 2011.

ÖZSOMER, A.; CALANTONE, R. J.; DI BENEDETTO, A. What makes firms more innovative? A look at organizational and environmental factors. Journal of Business \& Industrial Marketing, v. 12, n. 6, p. 400-416, 1997.

PENROSE, E. The theory of the growth of the firm. Oxford: Oxford University Press 1959.

PESTANA, M. H.; GAGEIRO, J. N. Análise de dados para ciências sociais. 5. ed. Lisboa: Silabo, 2008.

PORTER, M. E. Competitive advantage. New York: Free Press, 1985.

QUINELLO, R. Um ensaio sobre os efeitos colaterais da inovação. Revista Produção Online, v. 9, n. 2, p. 383-397, 2009.

REMLER, D. K.; VAN RYZIN, G. G. Research methods in practice: strategies for description and causation. Thousand Oaks: Sage Publications, 2011.

RICARDO, D. Princípios de economia política e tributação. 10. ed. São Paulo: Nova Cultural, 1996.

ROSENBUSCH N.; BRINCKMANN, J.; BAUSCH, A. Is innovation always beneficial? A meta-analysis of the relationship between innovation and performance in SMEs. Journal of Business Venturing, v. 26, n. 4, p. 441-445, 2011.

ROWE, W. G.; BARNES, J. G. Relationship marketing and sustained competitive advantage. Journal of Market Focused Management, v. 2, n. 3, p. 281-297, 1998.

SCHUMPETER, J. A. The theory of economic development. Cambridge: Harvard University Press, 1912.

SCHUMPETER, J. A. Capitalism, socialism and democracy. New York: Harper, 1942.

WERNERFELT, B. A resource-based view of the firm. Strategic Management Journal, v. 5, n. 2, p. 171-180, 1984. 
WERNERFELT, B. The resource-based view of the firm: ten years after. Strategic Management Journal, v. 16, n. 3, p. 171-174, 1995.

WILLIAMSON, O. E. The economic institution of capitalism: firms, markets, relational contracting. New York: The Free Press, 1985.

WILLIAMSON, O. The mechanisms of governance. New York: Oxford University Press, 1996.

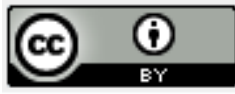

Artigo recebido em 28/08/2012 e aceito para publicação em 13/02/2014.

DOI: http://dx.doi.org/10.14488/1676-1901.v14.i1.1428 